\title{
Internal loop mutations in the ribosomal protein L30 binding site of the yeast L30 RNA transcript
}

\author{
SUSAN A. WHITE, MARGARET HOEGER, JAMES J. SCHWEPPE, AMANDA SHILLINGFORD, VALERIE SHIPILOV, \\ and JENNIFER ZARUTSKIE \\ Department of Chemistry, Bryn Mawr College, Bryn Mawr, Pennsylvania 19010, USA
}

\begin{abstract}
Yeast ribosomal protein $\mathrm{L30}$ binds to an asymmetric, purine-rich internal loop in its transcript to repress its own splicing and translation. The protein-bound form of the stem-internal loop-stem RNA is an example of a kink-turn RNA structural motif. Analysis of kink-turn motifs reveals that in $(2+5)$ internal loops, the identities of five nucleotides are very important, while the remaining two may be varied. Previous SELEX experiments on the L30 binding site showed an identical pattern of sequence variation with five nucleotides highly conserved and two positions variable. In this work, internal loop residues were mutated and tested for protein binding in vitro and in vivo. The two sheared G-A pairs, which cannot be mutated without severely weakening L30 binding, make sequence specific contacts with other portions of the RNA and L30 protein. In contrast, the lone nucleotide that protrudes into the protein and an unpaired adenosine make no sequence-specific contacts, and may be mutated without compromising L30 binding. The internal loop allows the formation of a very tight bend that brings the two stems together with cross-strand stacking of two adenines and an interhelical ribose contact. Replacement of a ribonucleotide with a deoxynucleotide adjacent to the internal loop weakens protein binding significantly. In the absence of L30, some of the internal loop residues involved in the formation of the kink-turn motif are protected from chemical modification, indicating that some elements of kink-turn structure may form in the free L30 RNA.
\end{abstract}

Keywords: RNA-binding protein; RNA internal loop; yeast ribosomal protein; chemical modification; kink-turn motif

\section{INTRODUCTION}

Saccharomyces cerevisiae ribosomal protein L30, formerly known as L32, is an essential yeast protein, and in addition to its role in the ribosome, binds to its own transcript and mRNA to inhibit splicing and translation, respectively (Dabeva and Warner 1987, 1993; Li et al. 1996; Mager et al. 1997). Its primary sequence is highly conserved across eukaryea and archaea, but no eubacterial version of L30 is thought to exist. For this reason it sometimes has the designation L30e. However, based on sequence and structural similarities, L30 is a member of the L7/L12 class of RNP proteins that includes eukaryotic, archael, and eubacterial

Reprint requests to: Susan A. White, Department of Chemistry, Bryn Mawr College, Bryn Mawr, PA 19010, USA; e-mail: swhite@brynmawr. edu; fax: (610) 526-5086.

Abbreviations: CMCT, 1-cyclohexyl-3-(2-morpholinoethyl) carbodiimide metho- $p$-toluene sulfonate; DMS, dimethylsulfate; BSA, bovine serum albumin; TBDMS, t-butyldimethylsilyl; NOE, Nuclear Overhauser Effect; SELEX, systematic evolution of ligands by exponential enrichment; IPTG, isopropylthiogalactose.

Article and publication are at http://www.rnajournal.org/cgi/doi/ 10.1261/rna.2159504. members (Koonin et al. 1994; Vidovic et al. 2000). L30 is known to act in a regulatory role in only one other species, Kluveromyces lactis, and it was the discovery of a common fold for the $5^{\prime}$ ends of the two RNA transcripts that originally led to the proposal of the stem-internal loop-stem architecture (Fig. 1A; Eng and Warner 1991). The protein binding site is a purine-rich, asymmetric internal loop whose primary sequence is important for high affinity protein binding (Li et al. 1995; Li and White 1997). SELEX experiments that tested the internal loop sequence requirements for protein binding underscored the importance of purines, and substitutions were only tolerated in two of seven loop nucleotide positions (Fig. 1B). The L30 system is thus an excellent system in which to explore the relationship between RNA primary sequence, structure, and protein binding.

An initial structural characterization of the L30 complex by NMR showed a highly stacked internal loop that brings the two helices together at an acute angle (Mao et al. 1999). An examination of the crystal structures of the Haloarcula marismortui large ribosome subunit and the $15.5-\mathrm{kD}$ protein/-U4 RNA spliceosomal complex revealed a common fold for several protein-bound RNAs. This fold is termed a 

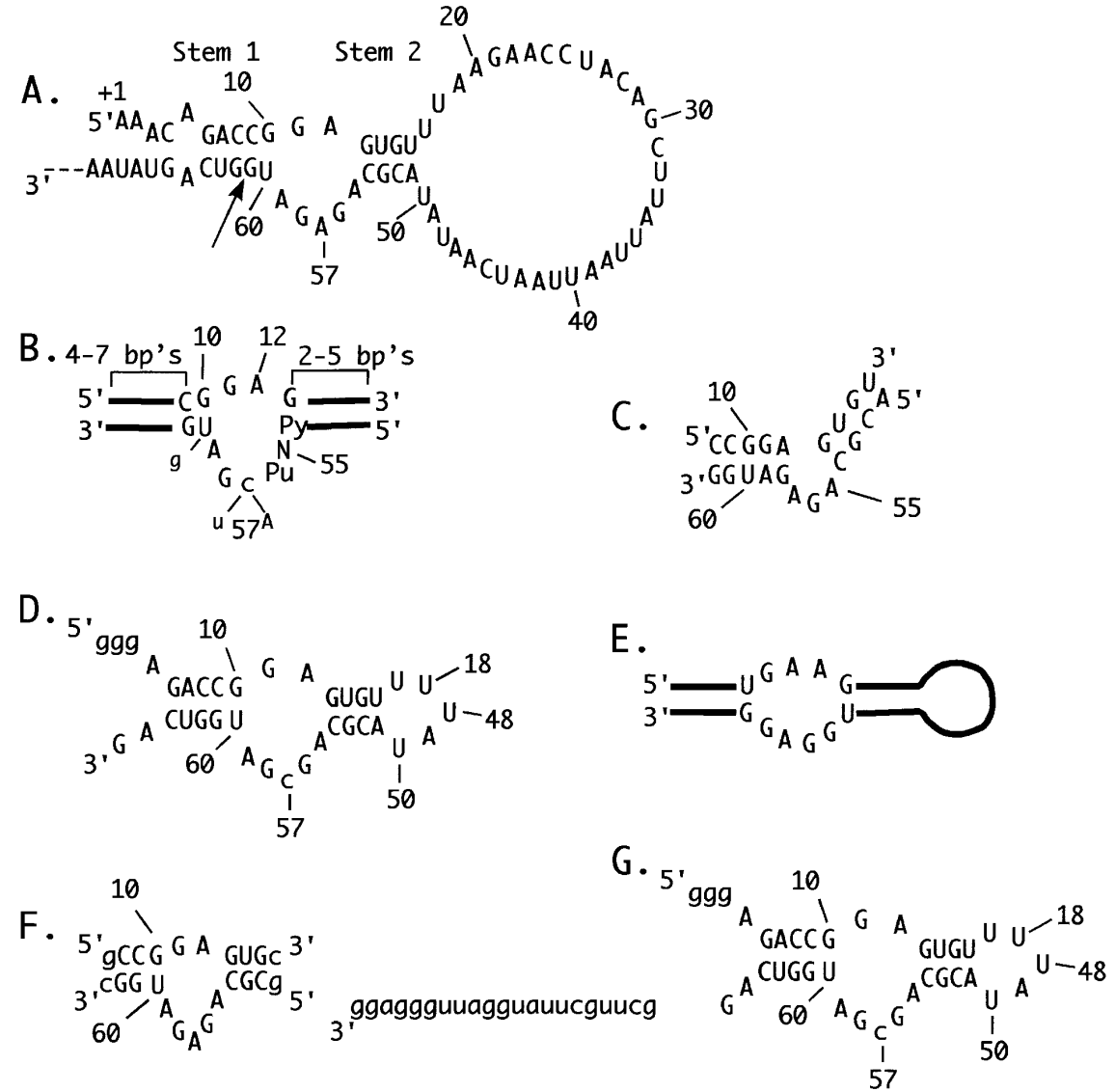

FIGURE 1. Secondary structures of L30 RNAs. Lowercase letters indicate nucleotides not found in the wild-type transcript. (A) The $5^{\prime}$ end of the wild-type L30 RNA transcript with an arrow indicating the $5^{\prime}$ splice site following the AUG start codon. (B) Summary of RNAs selected for L30 binding in SELEX experiment with lines indicating substitutions found in a minority of aptamers (Li and White 1997). (C) L30 RNA sequence written to emphasize the kink-turn structure (Klein et al. 2001). (D) Mini-C57 L30 RNA used for in vitro binding affinity measurements. (E) Proposed S. cerevisiae and E. coli ribosomal binding sites (Vilardell et al. 2000). (F) Duplex RNA composed of 10 and 13 nucleotide strands. (G) 3' tailed RNA used for primer extension experiments.

kink-turn (or K-turn), and with minor modifications, the bound form of the L30 RNA, as determined by NMR, may form a K-turn (Vidovic et al. 2000; Klein et al. 2001). The crystal structure of the L30 complex definitely confirms that the L30 RNA forms a K-turn (Hoggan et al. 2003; J. Chao and J. Williamson, pers. comm.). This motif is characterized by two sheared G-A pairs, two unpaired but stacked purines, and one nucleotide that extends into the protein. Figure 1C shows the kink-turn L30 site drawn with the paired loop nucleotides forming an extension to Stem I. The free L30 RNA has a more flexible structure than the bound form, and both RNA and protein become more ordered on complex formation (Mao and Williamson 1999a,b). In NMR experiments on the free L30 RNA, some internal loop residues had few NOEs, and some peaks were broadened due to loop dynamics. Thus, it was not possible to completely determine the RNA loop conformation in solution (Mao and Williamson 1999b).
Although in vitro selection (SELEX) experiments provided key information about RNA sequence elements required for protein binding, they did not provide an energetic estimate of the value of each potential RNA-protein or RNARNA contact. Furthermore, covariation of conserved purines was not found in SELEX experiments, and we wished to further investigate these conserved positions (Fig. 1B). For this reason, we decided to undertake an extensive series of mutagenic experiments. Twelve singly or doubly mutated small, model L30 RNAs (Fig. 1D) were constructed and tested in vitro for binding to wild-type L30 fusion protein. The L30 RNA kink appeared to be stabilized by close ribose contacts, so two deoxyribose substitutions were tested and found to weaken protein binding. In yeast cells, L30 acts as repressor of its own splicing and translation, so its ability to repress expression of a reporter protein in Escherichia coli was tested in vivo. Generally the mutagenesis work agreed with the SELEX results: RNAs having the same internal loop sequences as commonly selected aptamers bind L30 protein strongly, whereas those having internal loop sequences found rarely or not at all bind L30 protein much more weakly. Furthermore, the ability of the L30 protein to repress expression of the $\beta$-galactosidase reporter gene fused to L30 leader sequences was tested. Generally, transcripts having internal loop sequences that allowed high affinity L30 protein binding repressed expression of the reporter protein, whereas internal loops having weaker affinities allowed reporter expression. Thus, the in vivo repression abilities of the mutant L30 RNAs usually paralleled their protein affinities. Chemical modification experiments were conducted to determine whether internal loop residues might form base pairs, and indeed, several loop nucleotides adjacent to one stem were protected from chemical modification in the free RNA.

\section{RESULTS}

\section{RNA mutants support SELEX results}

In vitro selection experiments showed only a minority of the 13 residues tested were highly variable, and we refer to the invariant residues as "conserved." Residues 10, 11, 12, 58 , and 59 are invariant, while positions 55 and 57 tolerate 


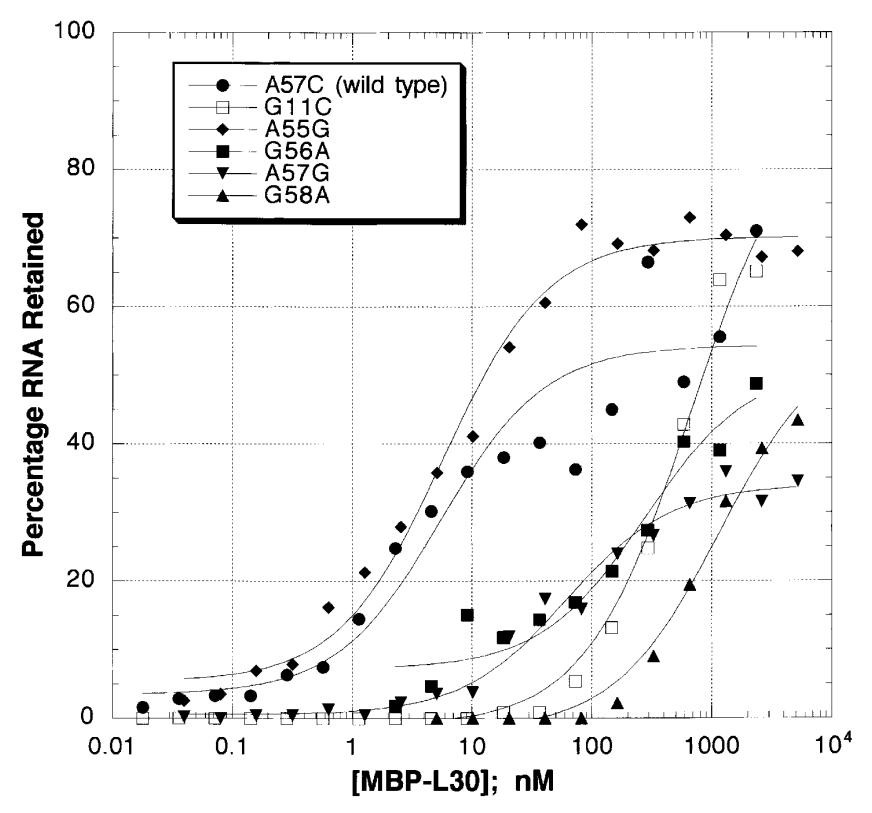

FIGURE 2. Binding isotherms for wild-type and selected mutant L30 RNAs binding to MBP-L30. All RNAs are variants of the RNA sequence shown in Figure 1D.

at least three different nucleotides (Fig. 1B). To confirm and quantify these results, single or double base mutations not found in the SELEX experiments were constructed, and the corresponding RNAs were tested for L30 maltose binding fusion protein (L30-MBP) binding in vitro. All RNAs were synthesized enzymatically, gel purified, and titrated with wild-type L30 fusion protein in electrophoretic bandshift and nitrocellulose filter binding experiments. It was possible to measure protein affinities for all mutants constructed despite not always being able to titrate sufficient protein to completely saturate the labeled RNA (Fig. 2). In previous work, we showed that C57 is found in most of the SELEX aptamers and that RNAs bearing this mutation, in place of the wild-type A, bind protein twice as strongly at the wildtype RNA (Li and White 1997). Because we anticipated making RNAs with weak protein affinities, C57 was included in most in vitro constructs to increase hard-to-measure weak binding affinities. This substitution for A57 was not included in most of the in vivo constructs because weak affinities correspond to high, easily measurable expression of the reporter gene. A57 does not interact with other nucleotides, and thus we anticipated that this mutation would not act synergistically with other mutations. In vivo binding affinities were measured in E. coli bearing two plasmids: a repressor plasmid that produced $\mathrm{L} 30$ protein, and a reporter plasmid bearing the L30 binding site just upstream from the $\beta$-galactosidase reporter gene. The reporter's expression was modulated by the binding of the L30 protein to its transcript's leader sequence.

The data indicate that of the RNAs shown in Figure 2, only L30-A55G has near wild-type protein affinity, while the other mutants bind significantly more weakly (Table 1 ). Parallel in vivo experiments that tested the ability of L30 to bind to the L30 sequence adjacent to a reporter gene's ribosome binding site showed that weak in vitro affinities are correlated with poor repression of the reporter gene. As expected, all of the nonselected mutants at the conserved positions $11,12,56,58$, and 59 had weak affinities for the L30-MBP protein. Mutation of the conserved G11 or A12 to $\mathrm{C}$ greatly decreased the affinity of the L30 fusion protein for the L30 RNA, and $\beta$-galactosidase expression was not repressed (Table 1). Purine substitutions at conserved positions G58 and A59 greatly weakened protein binding and completely abolished L30's ability to repress $\beta$-galactosidase production. Substitution of G56 with an A resulted in a moderate decrease in binding and with a $\mathrm{C}$, a further significant decrease in binding affinity. The former was found in the SELEX experiment, whereas the latter was not. The two-plasmid results showed that the G56A mutation showed fairly strong repression of $\beta$-galactosidase produc-

TABLE 1. Protein affinities and repression ratios of RNA mutants

\begin{tabular}{|c|c|c|}
\hline $\begin{array}{l}\text { RNA } \\
\text { (RNAs as in Fig. 1D) }\end{array}$ & $\begin{array}{l}\text { Dissociation } \\
\text { constant (nM) }\end{array}$ & Repression ratio \\
\hline A57 (wild type) & $30 \pm 10$ & 500 \\
\hline \multicolumn{3}{|l|}{ Single mutation RNAs } \\
\hline$\Delta \mathrm{G} 56^{\mathrm{a}}$ & Not detectable & 1 \\
\hline$\Delta \mathrm{A} 57^{\mathrm{a}}$ & Not detectable & 0.7 \\
\hline A57G & $60 \pm 20$ & 120 \\
\hline \multirow{2}{*}{$\begin{array}{l}\text { A57C (pseudo } \\
\text { wild-type) }\end{array}$} & $15 \pm 5$ & 810 \\
\hline & $\begin{array}{l}\text { RNAs having two } \\
\text { mutations (A57C } \\
\text { and the mutation } \\
\text { indicated) }\end{array}$ & $\begin{array}{l}\text { RNAs having a } \\
\text { single mutation }\end{array}$ \\
\hline G11C & $500 \pm 150$ & 1.6 \\
\hline $\mathrm{A} 12 \mathrm{C}$ & $1050 \pm 300$ & 1.1 \\
\hline A55G & $15 \pm 5$ & 160 \\
\hline G56A & $300 \pm 100$ & 260 \\
\hline G56C & $1200 \pm 400$ & 0.7 \\
\hline G58A & $1500 \pm 500$ & 0.7 \\
\hline A59G & $450 \pm 150$ & 0.5 \\
\hline \multicolumn{3}{|c|}{$\begin{array}{l}\text { Multiple mutation RNA } \\
\text { (RNAs as in Fig. 1E) }\end{array}$} \\
\hline "rRNA site" for E. coli & Not tested & 16 \\
\hline rRNA site for $S$. cer. & Not tested & 5 \\
\hline
\end{tabular}

Dissociation constants are reported for triplicate nitrocellulose binding assays using wild-type L30 fusion protein. Note that some RNAs used for filter binding experiments bear the A57C mutation that enhances protein binding.

${ }^{a}$ Denotes RNAs whose affinities were measured in Shipilov and White (2000). Repression ratios are the ratios of $\beta$-galactosidase produced, measured in Miller units, for cells producing no L30 protein and therefore high levels of $\beta$-galactosidase versus those where induced L30 protein binds to the L30 RNA sequence just 5' to the $\beta$-galactosidase gene and suppresses enzymatic expression. For the proposed ribosomal binding sites, the loop sequences are as in Figure 1E, but the stem sequences are as shown in Vilardell et al. (2000). 
tion, but the G56C mutant showed none. In contrast, the SELEX experiment showed that A55 could be A, C, or U, and the mutation experiments indicated that $G$ could be tolerated. However, the repression ratio for the $\mathrm{A} 55 \mathrm{G}$ point mutation is indicative of compromised protein-binding ability. A57G was the only nonselected substitution at that position, and this replacement had a relatively minor effect on the dissociation constant but significantly decreased the repression ratio. Consistent with the in vitro binding studies, the A57C construct repressed reporter protein expression twice as well as the wild-type construct.

In summary, mutation of the conserved G-A dinucleotide pair, G11-A59 and A12-G58, abolished L30 binding in both assays. At the two positions where RNA sequence variability is most tolerated, 55 and 57 , the in vitro assays suggested little sequence preference, but the two-plasmid assay did show more discrimination for reasons that we do not understand. At position 56, the binding and two-plasmid data both supported the purine preference, but in the in vivo assay the G56A repressed more strongly than would be anticipated based on its weak in vitro affinity. We note that this mutation is one found in the prototypical K-turn RNA motif (Klein et al. 2001). Although the frequency of finding a given aptamer sequence cannot be directly correlated with its protein binding energy, it is true that the data are surprisingly robust and that aptamer frequencies generally correlate with the relative ordering of binding energies.

Although the L30 autoregulatory binding site is well studied, its yeast ribosomal site has yet to be definitively identified. Based on primary sequence comparisons, Vilardell et al. (2000) identified several candidate yeast rRNA binding sites for L30, and RNAs containing one such site bound the L30 protein. This proposed ribosomal binding site for L30 contains a $(3+4)$ internal loop and represses $\beta$-galactosidase activity only modestly in the two-plasmid system (Fig. 1E; Table 1; Vilardell et al. 2000). Coincidentally, this sequence occurs in E. coli rRNA even though this organism does not have an L30 protein. The two putative sequences tested, from E. coli and yeast, have identical internal loop sequences, but differ slightly in their stems. The results of the in vivo binding assay suggest that the proposed rRNA binding sites bind L30 quite weakly, if at all.

\section{G10:U60 deoxyribose substitutions}

The results of previous work that explored all possible mutations at positions 10 and 60 indicated that G10 is especially important for L30 protein binding, that Watson-Crick pairs dramatically weaken binding, but that U60 is recognized as well (White and Li 1996). Based on these unusual sequence requirements, we hypothesized that a precise but somewhat flexible conformation might be required. In addition, the crystal structure shows close contact between the stems in the region of U60 (J. Chao and J. Williamson, pers. comm.). For this reason, it was decided to investigate RNAs bearing deoxyribose at positions 10 and 60. Ten and 13 nucleotide RNAs were chemically synthesized and annealed to form an RNA duplex (Fig. 1F). For electrophoretic experiments, radiolabeled and unlabeled RNAs were annealed, and fusion protein was incubated with the RNA mix (Fig. 3). Control lanes 9-12 in Figure 3 show that in the absence of fusion protein the RNA strands are singlestranded. Lanes 1-8 in Figure 3 are arranged in pairs having the same radiolabeled strand, with the complementary strand having either a ribose or deoxyribose at the 10 or 60 position. In every case, the deoxyribose sugar weakened L30 fusion protein binding. The strongest RNA-protein complex bands were for riboses at both the 10 and 60 positions (Fig. 3, lanes 6 and 8) and the weakest bands for deoxyriboses at the same positions, lanes 1 and 3. Of the mixed species, the ones bearing a ribose at the 60 position and a deoxyribose at the 10 position led to stronger binding than the converse (Fig. 3, lanes 4 and 5 versus lanes 2 and 7). To measure binding affinities, unlabeled annealed RNA duplexes were used as competitors to a pre-formed complex containing radiolabeled Mini-C57 RNA (Fig. 1D) and L30MBP fusion protein. The results of competition nitrocellulose filter binding experiments indicated that the effects of sugar mutation are roughly additive with the double deoxyribose duplex binding 10-fold more weakly while the G10deoxy binds twofold more weakly and U60-deoxy about

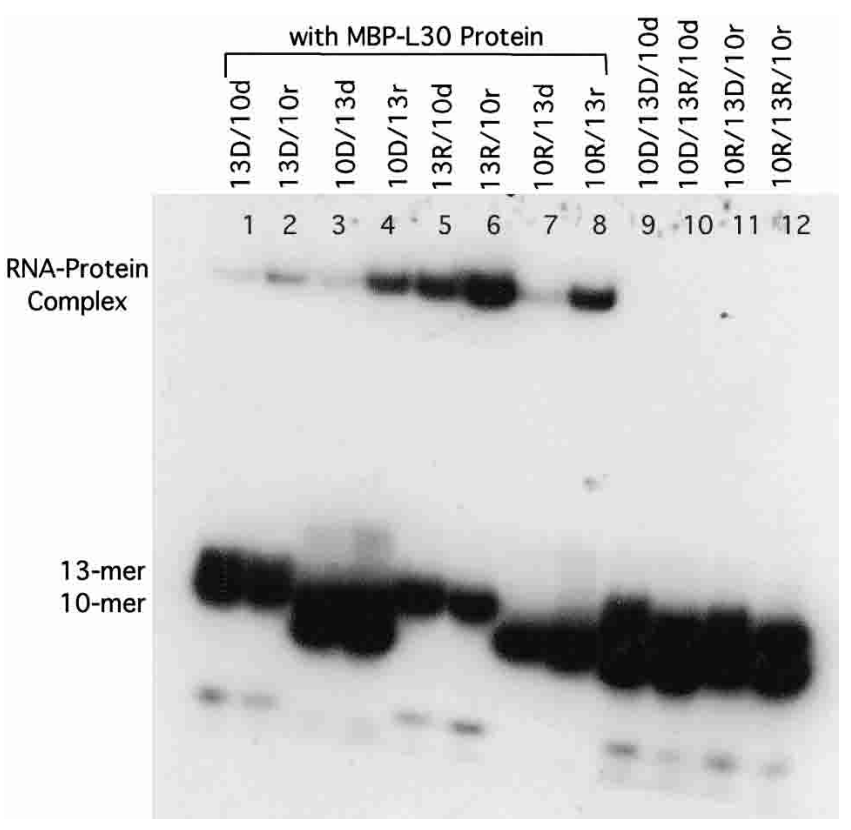

FIGURE 3. Binding of L30 fusion protein to $2^{\prime}$ deoxy substituted RNA oligomers. Lanes $1-8$ contain about $200 \mathrm{pM}^{32} \mathrm{P}$ end-labeled RNA oligomer, $60 \mathrm{nM}$ unlabeled RNA oligomer, and $200 \mathrm{nM}$ MBP-L30 fusion protein. The uppercase designation indicates the isotopically labeled RNA strand and whether the 10 mer or the 13 mer has a ribose or deoxyribose at position 10 or 60 , respectively, is indicated. Lanes 9-12 contain $200 \mathrm{pM}$ of two radiolabeled RNAs supplemented with 60 nM unlabeled RNA, but no L30 fusion protein. The gel was run at $4^{\circ} \mathrm{C}$ in TBE buffer. 
fivefold more weakly compared to the wild type (Table 2). Contrary to the mutation data that underscored the importance of G10, the ribose at the 60 position is the more critical one.

\section{Chemical modification of free RNA}

Given the tight structure of the protein-bound form of the RNA, we hypothesized that even the free RNA might have some elements of the kink-turn structure. The NMR data indicated that the L30 RNA in solution is more dynamic and less structured than the bound form, and we wished to use a complementary solution method to probe the structure of the internal loop region (Mao and Williamson $1999 b$ ). Because CMCT reacts with the N3 position of U and more slowly with the N1 position of G, this fairly bulky reagent can be used to determine if these atoms are accessible. Similarly, DMS reacts with the N1 position of A and may be used to determine the hydrogen bonding status or accessibility of the internal loop adenines. These two reagents were used to modify a version of the L30 RNA having a $3^{\prime}$ tail that allows primer binding (Fig. 1G). Modifications of N1 or N3 positions were then detected as reverse transcriptase stops. Parallel experiments were run at $65^{\circ} \mathrm{C}$ and $25^{\circ} \mathrm{C}$ to assess accessibility and reactivity under denaturing and native conditions, respectively.

It is evident that CMCT reactivity at $25^{\circ} \mathrm{C}$ was confined largely to residues in the L30 hairpin loop (Fig. 4, lane 4). Uridines 18,48 , and 50 were most reactive, but there is an extremely faint band corresponding to G56 and perhaps some reactivity indicated by the smeary band at G11. Uracils are more reactive than guanines, so it is hard to know if the guanine light bands are due to low inherent reactivity

TABLE 2. Binding affinities of $L 30$ fusion protein to $2^{\prime}$ deoxy substituted RNA oligomers

\begin{tabular}{lc}
\hline L30 RNA duplex & $\begin{array}{c}\text { Dissociation } \\
\text { (RNAs as in Fig. 1F) }\end{array}$ \\
\hline Constant (nM)
\end{tabular}

Each dissociation constant was measured by filter binding in triplicate where the indicated RNA duplex was titrated as a competitor against radiolabeled Mini-L30 RNA complexed with MBP-L30 fusion protein. Competition isotherms were fit to the equation below using KaleidaGraph (Abelbeck/Synergy).

\%Bound $=\frac{100}{2 T t}\left\{K_{t}+\frac{K_{t}}{K_{c}} C_{t}+P_{t}+T_{t}-\sqrt{\left(K_{t}+\frac{K_{t}}{K_{c}} C_{t}+P_{t}+T_{t}\right)^{2}-4 P_{t} T_{t}}\right\}$

where $T_{t}$ is the concentration of labeled RNA $(0.5 \mathrm{nM}), K_{t}$ is $K_{D}$ for the labeled RNA $(6 \mathrm{nM}), C_{t}$ is the concentration of the competitor RNA, $P_{t}$ is the fusion protein concentration $(50 \mathrm{nM})$, and $K_{c}$ is the competitor RNA $K_{D}$. Typical values for this assay are given in parentheses.

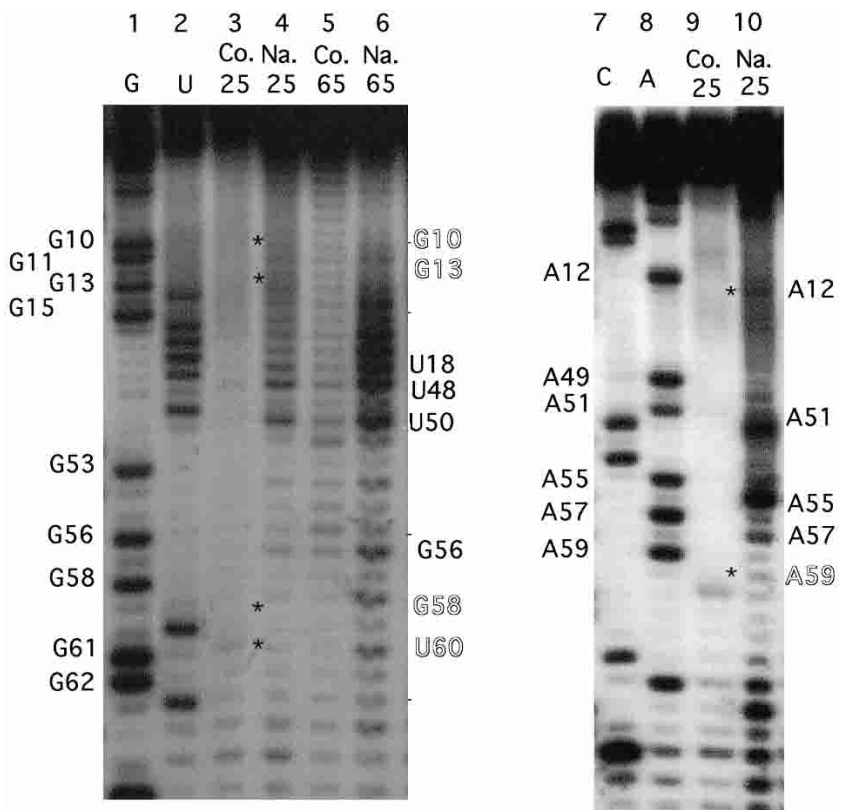

FIGURE 4. Chemical modification experiments designed to detect internal loop base pairing. Lanes $1-2$ and $7-8$ contain dideoxy sequencing reactions. Lanes 3,5 , and 9 are control reactions where the RNA was subjected to mock reactions at $25^{\circ} \mathrm{C}$ or $65^{\circ} \mathrm{C}$ (Co.). Lanes 4 and 6 contain native RNA reacted with CMCT at $25^{\circ} \mathrm{C}$ and $65^{\circ} \mathrm{C}$, and lane 10 shows RNA reacted with DMS at $25^{\circ} \mathrm{C}(\mathrm{Na})$. Note that the polymerase stops one nucleotide before the modification and that nucleotide positions in the sequencing lanes are indicated on the left. Nucleotides written on the right of the autoradiograms in solid are reactive to CMCT or DMSs, whereas as those written in shadow are wholly or partially protected, and the location of the missing or lighter band is indicated by an asterisk $\left(^{*}\right)$.

or to partial protection by hydrogen bonding (Ehresmann et al. 1987). The reactivity data at $65^{\circ} \mathrm{C}$ clearly showed that the first possibility is more likely correct (Fig. 4, lane 6). Thus, G10, G13, G58, and U60 were protected from CMCT attack. These data therefore support a helical conformation for G10-U60 and G58 in the free RNA. In contrast, the internal loop adenines were quite reactive to DMS. A51 and A55 were very reactive, whereas A57 and A12 were somewhat less reactive. The chemical modification experiments did indeed support a model for the internal loop where several nucleotides, G10, G13, G58, A59, and U60, were inaccessible to chemical modification, and this protection pattern is shown schematically in Figure 5A. The pattern of reactivity suggests that the portion of the internal loop adjacent to Stem I forms a solution structure that excludes both CMCT and DMS in the absence of protein.

\section{DISCUSSION}

The NMR and crystallographic high-resolution structures proposed for the L30 RNA-protein complex make it clear that most internal loop nucleotides are important either in stabilizing the RNA internal loop or in providing specific contacts for protein residues (Mao and Williamson 1999b; 

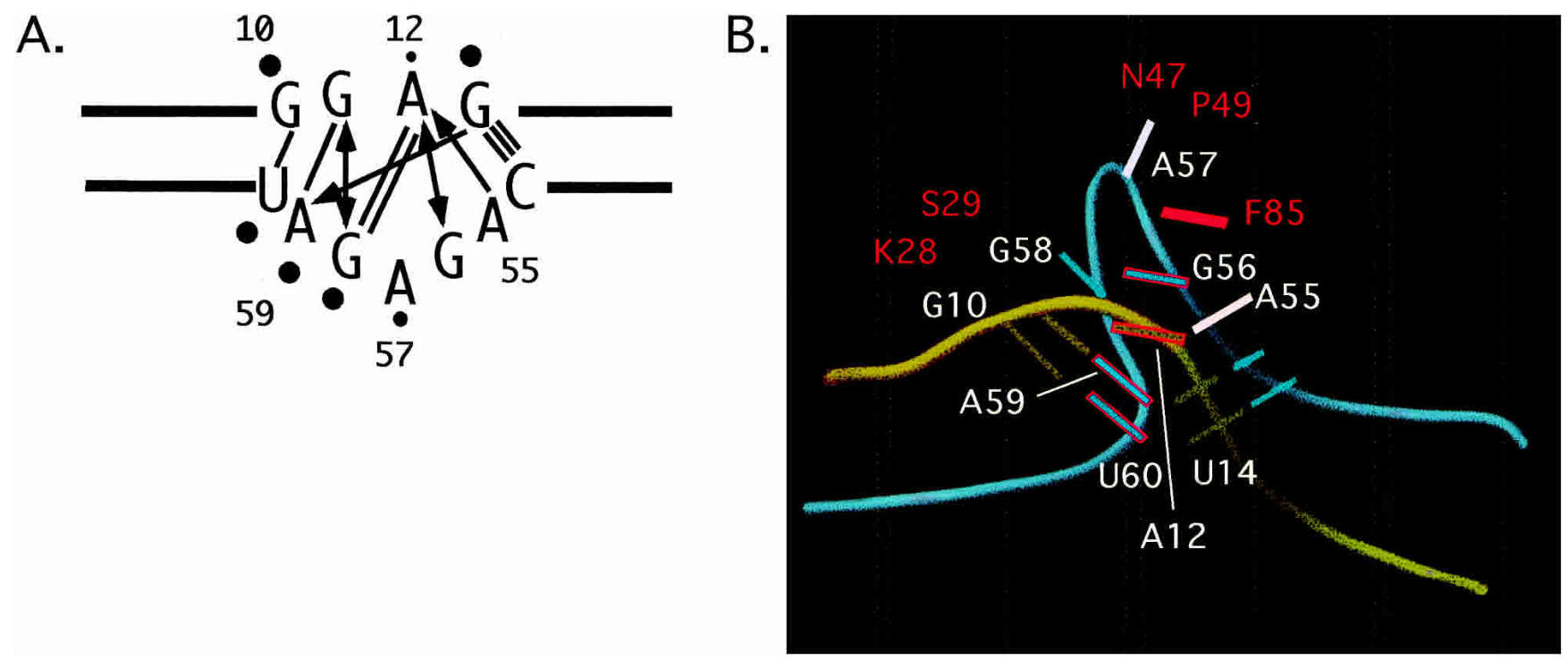

FIGURE 5. (A) Chemical reactivity of free RNA and hydrogen bonding of bound RNA. Black circles indicate purine N1 and the N3 of U protected from DMS or CMCT, and smaller circles indicate less protection. Solid lines indicate base-to-base hydrogen bonds and arrows ribose to purine hydrogen bonds. The arrowheads indicate N1 or O6 carbonyl groups and the tails the ribose 2' $\mathrm{OH}$. Double-headed arrows indicate two such reciprocal interactions. (B) Backbone structure of the L30 RNA bound to L30 based on the crystal structure. Nucleotides 7-18 are represented by the yellow tube and nucleotides 50-64 by the blue tube. This view emphasizes the five-residue stack that includes U60, A59, A12, G56, and F85, and these bases are outlined in red. The two variable nucleotides, A55 and A57, are shown in white and amino acids in red. The L30 complex coordinates were provided by J. Chao and J. Williamson (pers. comm.), and Sybyl (Tripos) was used to construct the backbone and Canvas (Deneba Systems) was used to draw the internal loop bases in their approximate positions.

Hoggan et al. 2003; J. Chao and J. Williamson, pers. comm.). Critical stacking and sequence-specific hydrogen bonds are based on the crystal structure and are shown schematically in Figure 5B. The protein-bound form of the L30 internal loop is organized such that the helical stacking continues into the loop to include all but one, residue A57. The four most conserved residues form two G-A pairs, and two unpaired purines cap off each stem with phenylalanine 85 completing the Stem I stack. Stem I is extended by stacking of the G10-U60 juxtaposition and the two sheared G-A pairs where G10, G11, and G58 all make sequence-specific protein contacts to K28 and S29 with their C6 carbonyl groups.

The crystal structure shows numerous base-to-base and base-to-sugar RNA contacts (J. Chao and J. Williamson, pers. comm.). The two RNA stems come together at an acute angle made possible by interhelical contacts along the inside of the kink. The N1 atoms of A12 and A59 contact the $\mathrm{A} 55$ and G13 2'OH groups, respectively, and G11 and G58 also make reciprocal N1 to 2' OH contacts (Fig. 5A). This cross-strand stacking of the A residues is somewhat similar to a reciprocal A-minor interaction and serves to bring the two stems together (Nissen et al. 2001). The sheared $\mathrm{G}$ and $\mathrm{A}$ interact with each other via some of their amino, N3 and N7 moieties, and this leaves the G N1-H, A $\mathrm{N} 1$, and G6 carbonyl available to contact the ribose or protein. Not surprisingly, mutation of any of these residues, whose base moieties are involved in RNA or protein contacts, weakens binding. Remarkably, A55 and A57, the most variable nucleotides, make no base-specific contacts. In agreement with the notion that the kink-turn motif may be an inherently thermodynamically stable structure, most of the residues comprising Stem I are at least partially protected from chemical modification in the absence of protein.

The two unpaired helix-capping protein residues, G56 and A55, provide an interesting contrast. The combined SELEX and mutagenesis results are that a purine is required at position 56, but any base is allowed at position 55. G56 stacks between F85 of the L30 protein and G58, whose O6 carbonyl is within hydrogen bonding distance of the $2^{\prime} \mathrm{OH}$ of A12. Although mutation to adenosine preserves the base stacking, it abolishes the carbonyl contact, so protein affinity is reduced. Mutation to a cytosine weakens RNA stacking and further weakens the protein binding. Although A55 stacks on the G13-C54 pair, only its ribose is capable of forming hydrogen bonds, and thus this residue may be mutated without compromising protein binding.

A57 protrudes into a loose, partial protein pocket composed of N47 and P49, and although the asparagine is a critical recognition element, any nucleotide at this position is tolerated. It may be possible for the amide moiety to hydrogen bond to each of the four bases as long as some conformational flexibility is allowed (Shipilov and White 2000). Interestingly, in the other RNA kink-turn studied by extensive mutagenesis, the protruding uridine 31 of the U4 snRNA is a critical $15.5-\mathrm{kD}$ spliceosomal protein recognition element and is structurally equivalent to the A57 of 
L30 RNA (Nottrott et al. 1999; Vidovic et al. 2000). Although A57 of the L30 RNA may not be deleted, it may be replaced by any nucleotide, but U31 of the U4 snRNA may not be mutated without weakening protein binding. This difference underscores the fact that this RNA K-turn motif employs a variety of protein recognition strategies (Nissen et al. 2001).

It is of interest to point out that the single-base deletion mutant RNAs, $\Delta$ G56 and $\Delta$ A57, have no apparent affinity for L30 and that no RNA aptamers have loop sizes differing from the two-opposite five-configuration. Yet, the putative ribosomal RNA binding site for L30 in four species contains a three-opposite four-purine internal loop closed by two G-U pairs (Fig. 1E; Vilardell et al. 2000). Competition and photocrosslinking experiments showed that the L30 protein has a weaker affinity for the rRNA compared to the mRNA. Results here are consistent with the proposed ribosomal site having significantly weaker binding to the L30 fusion protein. However, the three-opposite four-internal loop cannot form a kink-turn motif and, based upon modeling evidence, an alternate rRNA binding site was suggested for the extreme thermophile, Thermococcus celer (Chen et al. 2003).

\section{MATERIALS AND METHODS}

\section{RNAs and protein}

RNA oligonucleotides containing one deoxyribose nucleoside were ordered from the Nucleic Acid Synthesis Facility at the University of Pennsylvania. Either 2'-O-t-butyldimethylsilyl (TBDMS) or OFpmp (1-(2-fluorophenyl)-4-methoxypiperidin-1-yl) acetal 2' protecting groups were used (Cruachem). Some oligomers were HPLC purified on a reverse phase PrP-1 column from Hamilton. $5^{\prime}$ trityl groups were removed by acetic acid treatment that also removed the 2' Fpmp groups. TBDMS blocking groups were removed by incubation in triethlyamine trihydrofluoride (TEA. 3HF). Molar extinction coefficients were calculated as described by Borer of 94.1 OD 260/ $\mu$ mole for the 10 mer and 126.8 OD 260/ $\mu$ mole for the 13 mer (Fig. 1F; Borer 1975); 20 pmoles of each oligomer were incubated with $\gamma^{32}$ P ATP and T4 polynucleotide kinase and purified on a $20 \%$ denaturing gel. Labeled RNAs were visualized by autoradiography, excised from the gel, and extracted by soaking the crushed gel slice in $0.5 \mathrm{M} \mathrm{NaOAc}$ and $1 \mathrm{mM}$ EDTA. RNAs were extracted twice with buffer-saturated phenol, then ether, and finally ethanol precipitated with tRNA as a carrier. Alternatively, gel slices were rocked in room temperature buffer overnight, then the liquid was decanted and ethanol precipitated with carrier RNA.

For the chemical modification studies, a 74-nucleotide DNA template and an 11-nucleotide primer were ordered from the University of Pennsylvania Nucleic Acid Facility with cartridge purification. This DNA was annealed to the "top" 18 -mer promoter strand and transcribed from a partially double-stranded template using Ambion's MegaShort Script Kit (Lowary et al. 1985). An RNA secondary structure program was employed in the design of a primer-binding tail that would not interfere with the folding of the L30 binding site (Zuker 1989; Zuker et al. 1999). The resulting
RNA, whose length is 57 nucleotides, was gel purified as was the $5^{\prime}$ end-labeled 11-nucleotide DNA primer.

For internal loop mutation studies, RNA sequences that avoided obvious Watson-Crick base pairing across the internal loop were designed (Fig. 1D). DNA templates were ordered from the University of Pennsylvania Nucleic Acid Facility. Templates were annealed with the top strand of the T7 promoter, and transcription was carried out using Ambion's MegaShortscript kit. Transcripts were gel purified, phosphatased, $5^{\prime}$ end labeled, and gel purified as described above.

The construction of the maltose-binding protein-L30 (MBPL30) fusion construct is described elsewhere by Vilardell and Warner (1994), who provided JM109 cells bearing the L30 fusion plasmid. The fusion protein was prepared following the instructions for the NE Biolabs amylose column system. Protein concentrations were measured using the Bradford Assay (BioRad) calibrated against BSA. Later preparations included $0.1 \%(\mathrm{v} / \mathrm{v})$ neutralized polyethyleneimine to remove nucleic acids enabling direct spectroscopic measurement of fusion protein concentrations (Mao 1998).

\section{Protein-RNA binding by filter binding and electrophoretic bandshift}

Standard solution conditions for regular and competition binding assays were as follows: $75 \mathrm{mM} \mathrm{KCl}, 30 \mathrm{mM}$ Tris $(\mathrm{pH} 8), 2 \mathrm{mM}$ $\mathrm{MgCl}_{2}, 1 \mathrm{mM}$ DTT, $500 \mathrm{ng} / \mu \mathrm{L}$ BSA, $40 \mathrm{ng} / \mu \mathrm{L}$ tRNA, 0.05 unit $/ \mu \mathrm{L}$ RNAse inhibitor (Vilardell nad Warner 1994; Li et al. 1995). RNAs were renatured in $350 \mathrm{mM} \mathrm{KCl}, 30 \mathrm{mM}$ Tris ( $\mathrm{pH}$ 8), $10 \mathrm{mM}$ DTT. For direct titration of hairpin L30 RNAs, freshly diluted fusion protein was titrated into $50 \mu \mathrm{L}$ aliquots of binding mix that contained renatured, labeled RNA. For competition experiments, duplex RNAs were generally mixed and renatured at micromolar concentrations and subsequently diluted (White and Li 1996). Radiolabeled RNA was added to the binding mix containing sufficient fusion protein to reach $50 \%-80 \%$ saturation, aliquotted into $50 \mu \mathrm{L}$ binding reactions, and finally, titrated with competitor RNAs. The duplex RNAs are not stable under electrophoretic conditions in the absence of L30 protein, and we note that duplex RNAs used to produce L30 RNA-protein crystals had longer stems than the ones used in this work (Hoggan et al. 2003). Incubation was for $20 \mathrm{~min}$ at room temperature. For all experiments, the nitrocellulose filters were soaked in binding buffer then rinsed with $100 \mu \mathrm{L}$ cool binding buffer immediately following filtration. Filters were counted in Ecolume (ICN) scintillation fluid. Concentrations of RNAs were determined spectroscopically, and data were fit to either simple hyperbolic binding isotherms or competition curves using KaleidaGraph (Abelbeck/Synergy; Borer 1975; Weeks and Crothers 1992).

Electrophoretic bandshift experiments were run at room temperature or $8^{\circ} \mathrm{C}$ on $10 \%$ gels (29:1 acrylamide:bisacrylamide); 20 $\mu \mathrm{L}$ binding reactions containing $10 \%$ glycerol were loaded directly onto gels running in $0.5 \times \mathrm{TBE}(50 \mathrm{mM}$ Tris, $50 \mathrm{mM}$ boric acid, 1 mM EDTA).

\section{Measurement of repression ratios}

Plasmids and strains, including controls used in the Rev/RRE twoplasmid system, were a generous gift of Dr. Chaitanya Jain, and the 
details of plasmid construction, site-directed mutagenesis, and adaptation of the two-plasmid assay for L30 will be described elsewhere (Jain and Belasco 1996). Briefly, two plasmids were cotransformed into bacterial strain $\mathrm{WM} 1 / \mathrm{F}^{\prime}$. The repressor plasmid contains the gene for chloramphenicol resistance and expresses L30 in the presence of the inducer IPTG. The parent plasmid used for gene insertion, pACYC184, does not encode an RNA binding protein. The reporter plasmid, derived from pUC19 and encoding ampicillin resistance, contains an L30 RNA binding site just upstream of the ribosome binding site for the $\beta$-galactosidase gene (lac Z). Thus, in the absence of L30 protein capable of binding to mutated L30 RNA, high enzyme activity results. If the L30 protein can bind to the L30 binding site, ribosomal binding is repressed and less enzymatic activity is measured. In each duplicate assay, the $\beta$-galactosidase activity of mid-log phase cells containing both the repressor and reporter plasmids was compared to the enzyme activity of cell cultures grown in parallel having pACYC184 and a reporter plasmid. $\beta$-Galactosidase levels were measured using the Miller assay in which enzyme activities were measured spectroscopically using a chromogenic substrate (Miller 1972; Jain and Belasco 1997). The repression ratio is simply the concentration of $\beta$-galactosidase produced in the absence of the L30 repressor divided by the concentration of reporter protein produced in the presence of repressor. In all cases, Miller assays were more informative than blue/white colony screening on X-gal indicator plates.

\section{Chemical modification experiments}

Modification reactions were carried out as follows. A $2.5-\mu \mathrm{M}$ solution of the tailed L30 RNA (Fig. 1G) was renatured by heating to $90^{\circ} \mathrm{C}$ and slowly cooled. Magnesium chloride and sodium borate were added to final concentrations of $10 \mathrm{mM}$ and $50 \mathrm{mM}$, respectively. CMCT was added to a final concentration of $4.2 \mathrm{mg} / \mathrm{mL}$ to the RNA mix, and reactions were incubated at $65^{\circ} \mathrm{C}$ or $25^{\circ} \mathrm{C}$. DMS was added to a final concentration of $1 \%(\mathrm{v} / \mathrm{v})$ to an RNA mix buffered by cacodylate. Because the melting temperature of the RNA is expected to be about $57^{\circ} \mathrm{C}$, all of the uracils and guanosines should be equally reactive at the higher temperature, whereas regions of secondary structure should block the reaction at the lower temperature (Li et al. 1995). CMCT reactions were quenched on ice then ethanol precipitated, whereas the DMS reaction was stopped by addition of $\beta$-mercaptoethanol and incubation on ice. Parallel control reactions omitted only the CMCT or DMS (Hamann and Hou 1997).

Labeled primer $(60,000 \mathrm{cpm})$ was annealed to the modified RNA at $65^{\circ} \mathrm{C}$ and was allowed to cool to $47^{\circ} \mathrm{C}$, and each lane was loaded with the same amount of radioactivity. Deoxy and dideoxynucleotides and AMV reverse transcriptase (U.S. Biochemical) were allowed to react with the annealed hybrid at $47^{\circ} \mathrm{C}$ for $30 \mathrm{~min}$ according to the protocol supplied by U.S. Biochemical. Reactions were run on a $10 \%$ acrylamide gel at $80-90 \mathrm{~W}$ for $1-1.5 \mathrm{~h}$. Autoradiograms representing several independent experiments were inspected visually and by densitometry using Image J (http://rsb. info.nih.gov/ij). For the DMS reactions, internal loop adenines that reacted significantly less avidly than hairpin adenines were deemed to be protected. For the CMCT reactions of guanine and uracil, comparisons were made between the single-stranded and native reactivities at $65^{\circ} \mathrm{C}$ and $25^{\circ} \mathrm{C}$, respectively.

\section{ACKNOWLEDGMENTS}

We gratefully acknowledge the help and advice of Professors Walter Hill and Ya-Ming Hou and Dr. Christian Hamann in planning and conducting the chemical modification and primer extension experiments. We thank Professors James R. Williamson and KamBo Wong for sharing structural data in advance of publication, and Professor Chaitanya Jain for his help in setting up the twoplasmid system. This work was supported by grants from the National Science Foundation and the National Institutes of Health.

The publication costs of this article were defrayed in part by payment of page charges. This article must therefore be hereby marked "advertisement" in accordance with 18 USC section 1734 solely to indicate this fact.

Received October 8, 2002; accepted in revised form December 1, 2003.

\section{REFERENCES}

Borer, P.N. 1975. Handbook of biochemistry and molecular biology: Nucleic acids (ed. G. D. Fasman), 3rd ed., Vol. 1., p. 589. CRC Press, Cleveland, $\mathrm{OH}$.

Chen, Y.W., Bycroft, M., and Wong, K.B. 2003. Crystal structure of ribosomal protein $\mathrm{L} 30 \mathrm{e}$ from the extreme thermophile Thermococcus celer: Thermal stability and RNA binding. Biochemistry 42: 2857-2865.

Dabeva, M.D. and Warner, J.R. 1987. The yeast ribosomal protein L32 and its gene. J. Biol. Chem. 262: 16055-16059.

- 1993. Ribosomal protein L32 of Saccharomyces cerevisiae regulates both splicing and translation of its own transcript. J. Biol. Chem. 268: 16055-16059.

Ehresmann, C.F., Baudin, M., Mougel, P., Ebel, J., and Ehresmann, B. 1987. Probing the structure of RNAs in solution. Nucleic Acids Res. 15: 9109-9128.

Eng, F.J. and Warner, J.R. 1991. Structural basis for the regulation of splicing of a yeast messenger RNA. Cell 65: 797-804.

Hamann, C.S. and Hou, Y.-M. 1997. An RNA structural determinant for tRNA recognition. Biochemistry 36: 7967-7972.

Hoggan, D.B., Chao, J.A., Prasad, G.S., Stout, C.D., and Williamson, J.R. 2003. Combinatorial crystallization of an RNA-protein complex. Acta Crystallogr. D59: 466-473.

Jain, C. and Belasco, J.G. 1996. A structural model for the HIV-1 REV-RRE complex deduced from altered-specificity REV variants isolated by a rapid genetic strategy. Cell 87: 115-125.

-1997. A rapid genetic method for the study of RNA binding proteins. In $m R N A$ formation and function, pp. 263-284. Academic Press, New York.

Klein, D.J., Schmeing, T.M., Moore, P.B., and Steitz, T.A. 2001. The kink-turn: A new RNA secondary structure motif. EMBO J. 20: 4214-4221.

Koonin, E.V., Bork, P., and Sander, C. 1994. A novel RNA-binding motif in omnipotent suppressors of translation termination, ribosomal proteins and a ribosome moidification enzyme? Nucleic Acids Res. 22: 2166-2167.

Li, H. and White, S.A. 1997. RNA aptamers for yeast ribosomal protein L32 have a conserved purine-rich internal loop. RNA 3: 245254.

Li, H., Dalal, S., Kohler, J., Vilardell, J., and White, S. 1995. Characterization of the pre-mRNA binding site for yeast ribosomal protein L32: The importance of a purine-rich internal loop. J. Mol. Biol. 250: 447-459. 
Li, B., Vilardell, J., and Warner, J.R. 1996. An RNA structure involved in feedback regulation of splicing and of translation is critical for biological fitness. Proc. Natl. Acad. Sci. 93: 1596-1600.

Lowary, P., Sampson, J., Milligan, J., Groebe, D., and Uhlenbeck, O.C. 1985. Structure and dynamics of RNA: A better way to make RNA for physical studies (NATO ASI Series) (ed. C. Hilbers), pp. 69-76. Plenum Press, New York.

Mager, W.H., Planta, R.J., Ballesta, J.-P.G., Lee, J.C., Mizuta, K., Suzuki, K., Warner, J.R., and Woolford, J. 1997. A new nomenclature for the cytoplasmic ribosomal proteins of Saccharomyces cerevisiae. Nucleic Acids Res. 25: 4872-4875.

Mao, H. 1998. Structure determination of a yeast ribosomal protein L30 and pre-mRNA binding site complex by NMR spectroscopy. Massachusetts Institute of Technology, Cambridge, MA.

Mao, H. and Williamson, J.R. 1999a. Local folding coupled to RNA binding in the yeast ribosomal protein L30. J. Mol. Biol. 292: 345359.

- 1999b. Assignment of the L30-mRNA complex using selective isotopic labeling and RNA mutants. Nucleic Acids Res. 27: 40594070.

Mao, H., White, S.A., and Williamson, J.R. 1999. Structure of the yeast RPL30-autoregulatory RNA complex revealing a novel loop-loop recognition motif. Nat. Struct. Biol. 6: 1139-1147.

Miller, J. 1972. Experiments in molecular genetics. Cold Spring Harbor Press, Cold Spring Harbor, New York.

Nissen, P., Ippolito, J.A., Ban, N., Moore, P.B., and Steitz, T.A. 2001. RNA tertiary interactions in the large ribosomal subunit: The Aminor motif. Proc. Natl. Acad. Sci. 98: 4899-4903.
Nottrott, S., Hartmuth, K., Babrizo, P., Urlaub, H., Vidovic, I., Ficner, R., and Lührmann, R. 1999. Functional interaction of a novel $15.5 \mathrm{kD}$ [U4/U6.U5] tri-snRNP protein with the $5^{\prime}$ stem-loop of U4 snRNA. EMBO J. 18: 6119-6133.

Shipilov, V. and White, S.A. 2000. Conserved asparagine makes an essential contact to an RNA adenosine or cytidine. J. Biomol. Struct. Dyn. 11: 75-79.

Vidovic, I., Nottrott, S., Hartmuth, K., Lührmann, R., and Ficner, R. 2000. Crystal structure of the spliceosomal $15.5 \mathrm{kD}$ protein bound to a U4 snRNA fragment. Mol. Cell 6: 1331-1342.

Vilardell, J. and Warner, J.R. 1994. Regulation of splicing at an intermediate step in the formation of the spliceosome. Genes \& Dev. 8: $211-220$.

Vilardell, J., Yu, S.J., and Warner, J.R. 2000. Multiple functions of an evolutionarily conserved RNA binding domain. Mol. Cell 5: 761766.

Weeks, K.M. and Crothers, D.M. 1992. RNA binding assays for tatderived peptides: Implications for specificity. Biochemistry 31: 10281-10287.

White, S.A. and Li, H. 1996. Yeast ribosomal protein L32 recognizes an RNA G:U juxtaposition. RNA 2: 226-234.

Zuker, M. 1989. On finding all suboptimal foldings of an RNA molecule. Science 244: $48-52$.

Zuker, M., Mathews, D.H., and Turner, D.H. (eds. J. Barciszewski and B.F.C. Clark), pp. 11-43. 1999. Algorithms and thermodynamics for RNA secondary structure prediction: A practical guide. In RNA biochemistry and biotechnology (NATO ASI Series). Kluwer Academic Publishers, Dordrecht, NL. 

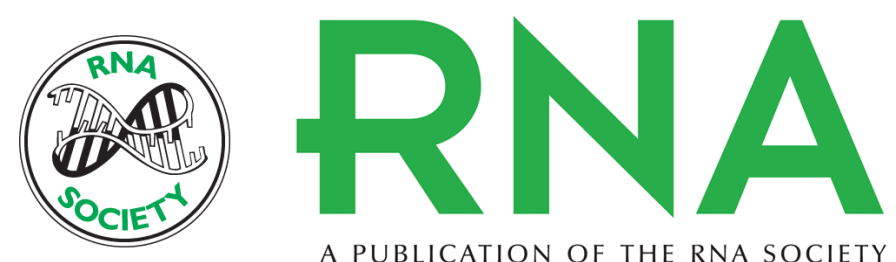

A PUBLICATION OF THE RNA SOCIETY

\section{Internal loop mutations in the ribosomal protein L30 binding site of the yeast L30 RNA transcript}

SUSAN A. WHITE, MARGARET HOEGER, JAMES J. SCHWEPPE, et al.

RNA 2004 10: 369-377

References This article cites 25 articles, 9 of which can be accessed free at: http://rnajournal.cshlp.org/content/10/3/369.full.html\#ref-list-1

License

Email Alerting Receive free email alerts when new articles cite this article - sign up in the box at the Service top right corner of the article or click here.

To subscribe to RNA go to:

http://rnajournal.cshlp.org/subscriptions 